\title{
Е.Е. Порфирьев
}

\section{МОДЕЛИРОВАНИЕ ТЕКУЩИХ ТЕНДЕНЦИЙ НА РОССИЙСКОМ РЫНКЕ ТРУДА}

\begin{abstract}
В статье изложены создание и анализ агент-ориентированной модели, отражающей текущее состояние на российском рынке труда. Целью работы является создание модели, описывающей современную ситуацию на рынке труда и способной стать базой для моделирования сиенариев развития ситуации. Научная новизна статьи выражается в применении метода агентного моделирования по отношению к современной ситуации на российском рынке труда. Помимо моделирования текущей ситуации, предложены два альтернативных сценария: занятость безработных на общественных работах и общественные работы, создание государством новых рабочих мест, обеспечивающих постоянную занятость. Построение альтернативньх сценариев дало возможность графически отразить влияние мер государственной поддержки на уровень занятости. Подсчитаны вероятные объемы финансирования общественных работ. Результатом исследования является вывод о высокой нагрузке для бюджета, которую может вызвать политика общественных работ. По итогам исследования была получена модель рынка труда, которая может быть пригодна для использования студентами экономического профиля, а также при проведении прикладных исследований.

Ключевые слова: агент-ориентированные модели, безработица, математическое моделирование, общественные работы, рынок труда, трудовые ресурсы, экономические агентыл.
\end{abstract}

Современная российская экономика переживает очередной период структурных изменений, связанных как с объективными экономическими факторами, так и с новыми внешнеполитическими условиями. Можно утверждать, что период роста, основанного на эффекте низкой базы, что было свойственно первому десятилетию XXI в., завершился.

Современная российская экономика сталкивается с двумя глобальными вызовами - падением потребительской активности и снижением инвестиций. Из-за чувствительности экономики к цене на углеводородные ресурсы национальная валюта испытывает сильнейшее давление, что разгоняет инфляцию по причине значительной доли импорта в структуре потребления как домохозяйств, так и коммерческого сектора. Последний особенно зависим от импортных технологий, оборудования и комплектующих.

В сложившихся непростых условиях российское правительство вынуждено, с одной стороны, сдерживать инфляцию, с другой - стараться не допустить дальнейшего снижения спроса, которое всегда влечет за собой рост безработицы. Данная задача является нетривиальной, поскольку макроэкономические показатели инфляции и безработицы связаны между собой. Низкая безработица зачастую стимулирует инфляцию и наоборот [2]. В условиях, когда ресурсы особенно ограничены, цена ошибки возрастает. Для минимизации рисков необходимо произвести анализ текущей ситуации путём её мо- 
делирования $[8,12]$. Опираясь на этот базис, можно будет смоделировать предлагаемые изменения и увидеть последующий эффект [6, 7].

Данная работа посвящена описанию текущей ситуации на российском рынке труда через представление последнего как совокупности индивидов. Следует сказать, что российский рынок труда обладает своими характерными чертами [13], одна из которых - высокая адаптивность к кризисным явлениям в экономике [14].

В статье рассмотрена «карта состояний» индивидов, которая отражает позицию человека на рынке труда [1]. Для построения модели использован программный комплекс AnyLogic.

При изучении российского рынка труда мы используем метод агентного моделирования, суть которого заключается в представлении домохозяйств, фирм и отдельных людей [5]. Поскольку рынок труда такой страны, как Россия, является весьма сложной системой, в модели рассмотрена популяция из 10000 агентов. Все агенты в данном случае представляют собой индивидов в трудоспособном возрасте на российском рынке труда. Каждый индивид может иметь одно из нижеперечисленных состояний в конкретный момент времени:

- имеет работу;

- безработный;

- безработный более 12 месяцев.

Период в 12 месяцев был выбран в качестве разделителя между обычной безработицей и той стадией, когда безработица приобретает черты хронической.

Рассмотрим подробнее представленные на схеме состояния (рис. 1).

- defaultState - это состояние, в которое попадает индивид сразу же из точки входа. Фактически это его начальное состояние на рынке труда до того момента, пока он не нашел работу или не встал на биржу труда;

- Work - состояние, в котором индивид имеет работу;

- noWork - состояние безработицы. В рамках модели состояние безработицы приравнивается к учету индивида на бирже труда, так как считается рациональной моделью поведения индивида;

- chronicalNoWork - состояние хронической безработицы. Под хронической подразумевается безработица, длящаяся более 12 месяцев.

При построении модели программный комплекс AnyLogic оперирует понятием интенсивности перехода агентов между состояниями. И хотя интенсивность определяется вероятностью изменения состояний агента, она не является прямой аналогией вероятности. Так, например, сумма всех вероятностей должна в итоге давать $100 \%$ (или единицу). Однако когда мы говорим о той интенсивности, с которой экономические агенты переходят из одного состояния в другое, то данное условие уже является неприменимым.

Для определения вероятности, с которой экономические агенты переходят из одного состояния в другое, были использованы данные Федеральной службы государственной статистики (Росстат). Вероятность, с которой агент может попасть в то или иное состояние, влияет на интенсивность перехода агентов между состояниями. Необходимые значения берутся по данным о рынке труда, собранным Росстатом. 
Согласно оценке Федеральной службы государственной статистики, в ноябре 2015 г. численность экономически активного населения России составила 76,6 млн чел., или 53\% от общей численности населения страны [4]. Из них 72,2 млн чел. были заняты в экономике, что составляет $94,2 \%$ от экономически активного населения. Безработными были признаны 4,4 млн, или $5,8 \%$ от экономически активного населения. Эти лица не имеют занятия, но активно ищут его, что соответствует понятию безработного в методологии Международной организации труда [17].

Данные показатели задают в модели величины интенсивности перехода агентов в состояния Work и noWork.

Из состояния noWork индивид может перейти либо в состояние Work, ecли он нашел работу, либо в состояние chronicalNoWork, если работа не была найдена в течение 12 месяцев.

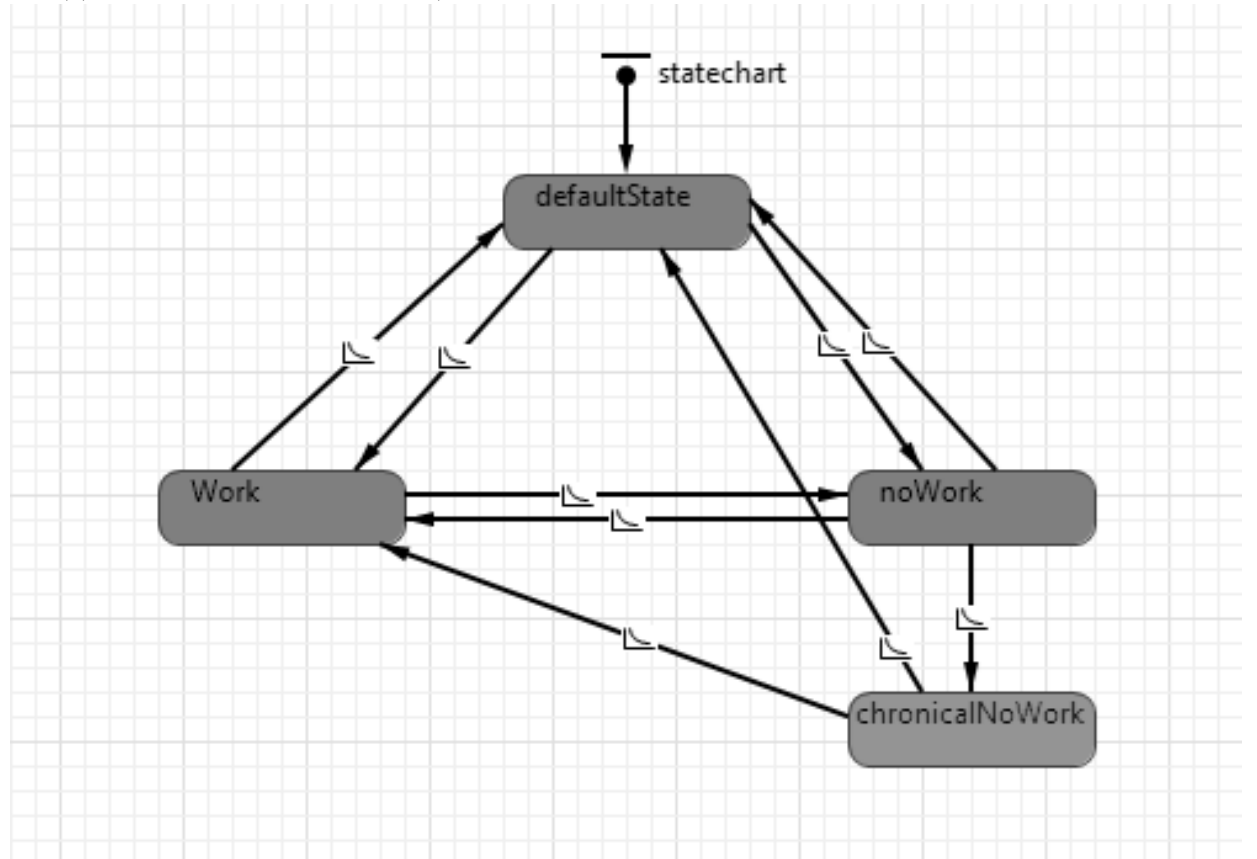

Рис. 1. Карта состояний модели: сценарий без государственной поддержки

По данным Федеральной службы государственной статистики, 27,1\% ищущих работу ищут её более 12 месяцев, что и определяет интенсивность перехода экономического агента в состояние chronicalNoWork.

Стоит отметить, что человек, находящийся в состоянии Work, noWork или chronicalNoWork, может покинуть рынок труда. В рамках модели это означает возвращение в состояние defaultState. Уход с рынка труда может быть вызван смертью гражданина, инвалидностью или выходом на пенсию. В данном случае под выходом на пенсию нужно понимать не достижение пенсионного возраста, а прекращение пенсионером трудовой деятельности. Таким образом, для измерения интенсивности возвращения агентов в состояние defaultState необходимо отследить изменение численности рабочей силы. 
Кроме работающих пенсионеров, на рынке труда также присутствует молодежь в возрасте до 18 лет. Учитывая вышеперечисленные факторы, будем опираться на понятие рабочей силы, изложенное Федеральной службой государственной статистики, а именно лица 15-72 лет, которые в рассматриваемый период считаются занятыми или безработными (таблица).

Доля рабочей силы в России в различные годы [15]

\begin{tabular}{c|c|c|c}
\hline Год & Всё население, тыс. чел. & $\begin{array}{c}\text { Рабочая сила, } \\
\text { тыс. чел. }\end{array}$ & $\begin{array}{c}\text { Доля рабочей силы, } \\
\%\end{array}$ \\
\hline 2005 & 143236,6 & 112177 & 78,3 \\
\hline 2013 & 143666,9 & 108993 & 75,9 \\
\hline 2014 & 146267,3 & 110226,3 & 75,4 \\
\hline
\end{tabular}

Сокращение доли рабочей силы означает, что с рынка труда в относительных величинах выходит больше людей, чем на него поступает. Стоит также отметить, что данные за 2014 г. взяты с учетом Крыма и Севастополя, что, безусловно, оказывает влияние. Тем не менее тренд на уменьшение доли рабочей силы прослеживался и до 2014 г.

Для вычисления среднемесячного темпа уменьшения рабочей силы нам необходимо найти соотношение рабочей силы 2014 и 2005 гг., после чего поделить его на количество месяцев. Поскольку рабочая сила 2014 г. составляет $98,3 \%$ от рабочей силы 2005 г., среднемесячное изменение составит $0,016 \%$ относительно численности рабочей силы в 2005 г. Так как модель использует шаг величиной в месяц, то полученная величина будет являться интенсивностью перехода агентов в состояние defaultState.

В то же время, если сравнить данные 2013 и 2005 гг., то мы увидим, что рабочая сила 2013 г. составляет 97,2\% от величины 2005 г., а среднемесячное изменение - 0,03\%. Фактически российский рынок труда пережил огромный прирост рабочей силы, аналогичный миграционному. При этом все эти люди являются новыми полноценными гражданами, могут свободно перемещаться по территории России и осуществлять трудовую деятельность.

Обработанные моделью данные показывают текущую ситуацию на рынке труда. Несмотря на незначительные колебания уровня безработицы в целом, мы видим, что система находится в некотором равновесном состоянии. Это обусловлено тем, что при построении системы не заданы предпосылки, способные оказывать влияние на рынок труда. В нынешнем состоянии модель описывает существующее положение вещей. Ось абсцисс отображает прошедшие месяцы, ось ординат - количество агентов в том или ином состоянии (рис. 2).

Введем новые факторы и посмотрим, как на это отреагирует модель. Одним из главных участников рынка труда, способным больше других влиять на ситуацию, является государство. Благодаря такому инструменту, как фиатные деньги, государство способно создавать рабочие места в больших масштабах.

Наиболее известен пример общественных работ, введенных администрацией президента Рузвельта в качестве одной из мер борьбы с экономическим кризисом, названным Великой депрессией. Безработные привлекались к 
строительству дорог, мостов, аэродромов и других инфраструктурных проектов, уборке улиц и даже к работе фотокорреспондентами, которые и сделали большинство фотографий времен Великой депрессии [9].

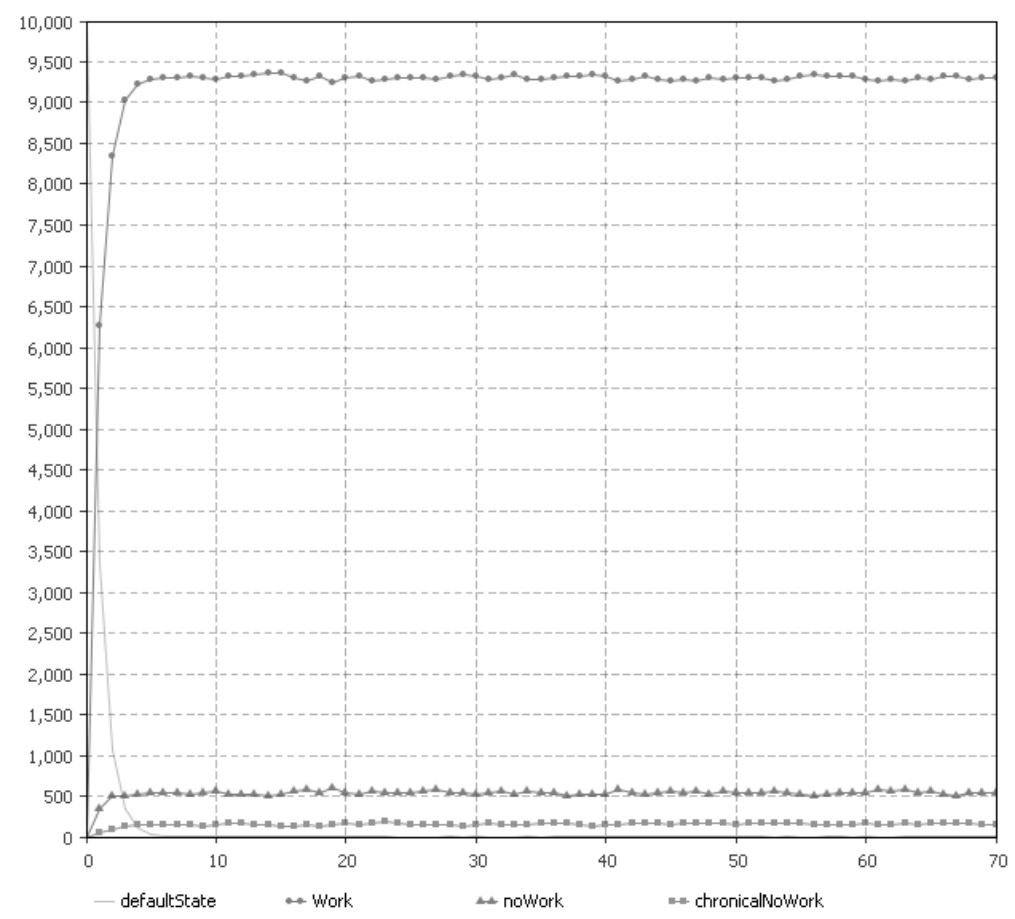

Рис. 2. Результат запуска сценария без государственной поддержки

Безусловно, политика общественных работ требует больших затрат со стороны государства. Так как фиатные деньги базируются на авторитете государства (напомним, что п. 1 ст. 140 Гражданского кодекса Российской Федерации гласит: «Рубль является законным платежным средством, обязательным к приему по нарицательной стоимости на всей территории Российской Федерации» [3]), последнему требуется взвешенность в действиях, чтобы инфляция не вышла из-под контроля. Главная цель общественных работ запустить маховик экономического роста до того, как инфляция начнет разрушать национальную экономику [16].

Итак, введем в модель предпосылку, что безработные, не нашедшие за 12 месяцев работу, привлекаются к общественным работам сроком на полгода, после чего снова выходят на рынок труда в качестве соискателей. Если во время общественных работ человек находит работу - он переходит на новое постоянное место труда (рис. 3).

Подобные предпосылки убрали из модели состояния chronicalNoWork и заменили его состоянием socialWork, которое отражает участие гражданина в общественных работах. Заметим, что схема переходов агентов из состояния в состояние немного изменилась. Так, например, агент способен вернуться из 
состояния socialWork к noWork, если за полгода им так и не была найдена работа.

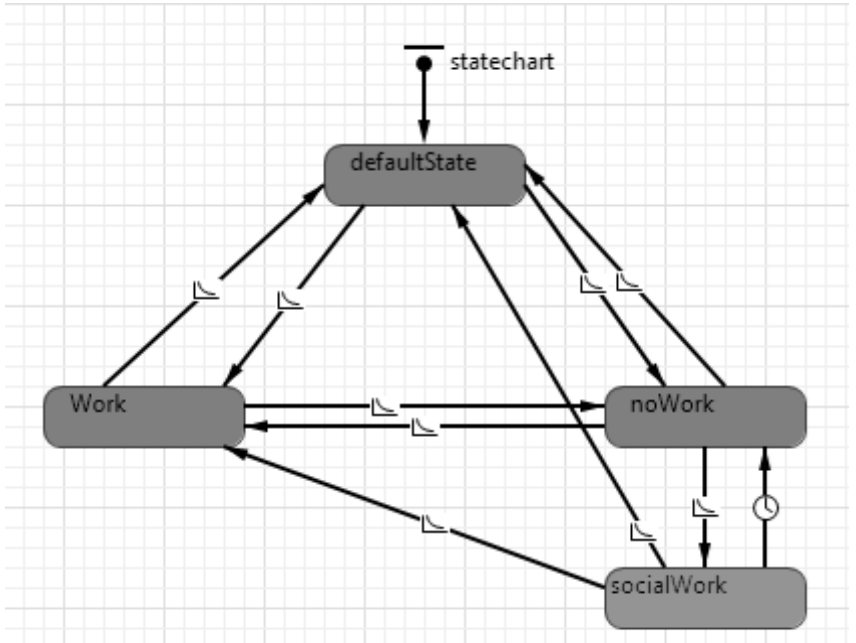

Рис. 3. Карта состояний модели: сценарий общественных работ

В отличие от прочих переходов, определяемых интенсивностью, данный переход осуществляется по таймеру, а именно после 6 месяцев пребывания в состоянии socialWork.

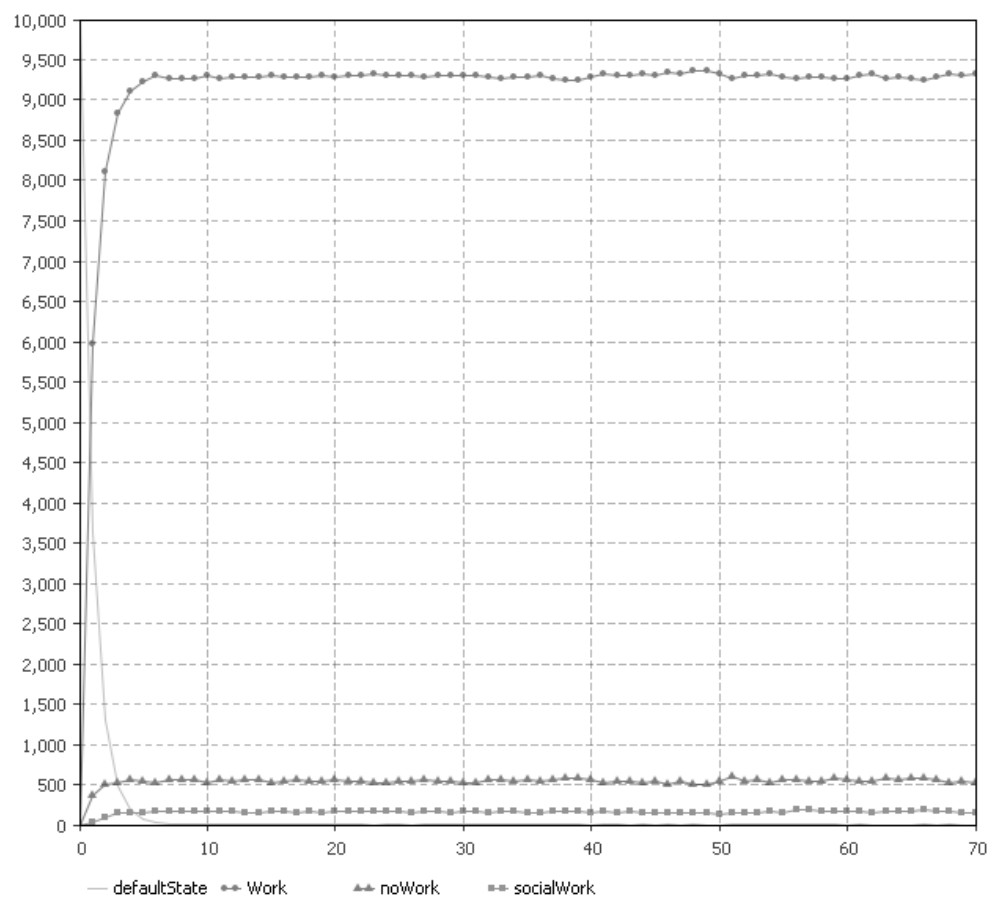

Рис. 4. Результат запуска сценария с общественными работами 
Общественные работы помогли снизить безработицу до естественного уровня, однако не стали альтернативой полноценной занятости. Из представленного графика также видно, что общественные работы стабилизировали число занятых на постоянных рабочих местах в первые три года по сравнению с базовым сценарием (рис. 4). Предположим, что государство готово создавать постоянные рабочие места. Посмотрим, как это скажется на рынке труда и во сколько это обойдется государству.

Предположим, что создание новых рабочих мест повышает вероятность для тех, кто занят на социальных работах, устроиться на постоянную работу на $1 \%$. Это повышение вероятности вызывает изменение интенсивности перехода агентов из состояния socialWork в состояние Work с 0,942 до 0,952 .

Что такое увеличение вероятности устроиться на работу на $1 \%$ для представленной популяции в 10000 экономических агентов? Фактически в данной модели государство создало 100 новых рабочих мест. Поскольку рассматриваемая система является замкнутой, увеличение рынка труда на 100 рабочих места уменьшает вероятность потери работы для работающих агентов. Это значит, что интенсивность перехода агентов из состояния Work в состояние noWork снижается.

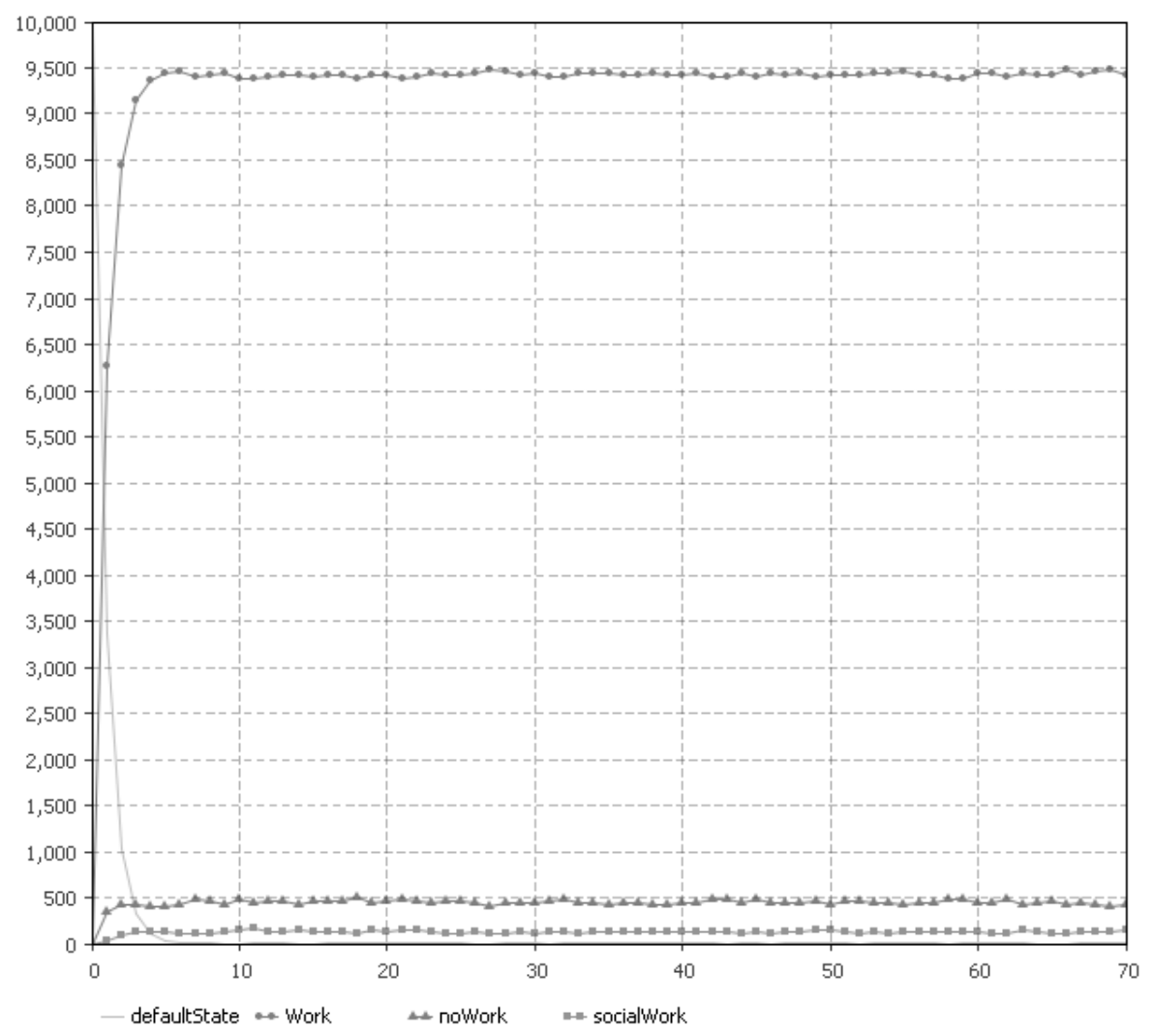

Рис. 5. Результат запуска сценария с созданием новых рабочих мест 
Как видно из графика (рис. 5), подобная политика способствует росту уровня занятости. Показатель безработицы снижается до естественного уровня в 5\%, а количество занятых на социальных работах в целом сводится к минимуму.

Остается вопрос затрат на проведение такой политики со стороны государства. Согласно данным Федеральной службы государственной статистики, в России 1092 тыс. человек искали работу 12 месяцев и более, что делает их кандидатами для общественных работ [15]. Из тех же данных следует, что среднемесячные затраты на рабочую силу (не путать со средней заработной платой) составляли 45870,2 руб. В этих затратах непосредственно на заработную плату уходит 75\%. Остальное - это расходы на социальную защиту и прочие расходы. В свою очередь, минимальный размер оплаты труда в России составляет 6204 руб. [10], таким образом, в этом случае расходы на рабочую силу для работодателя составляют 8272 руб.

Две эти величины можно представить как минимум и максимум в случае с оплатой общественных работ. Выбор подобного максимального значения обусловлен тем, что оплата общественных работ не должна превышать средний уровень оплаты труда, иначе это станет демотивирующим фактором при поиске работы соискателями.

Безусловным является то, что в целях более детализированного исследования стоит разбить данные по затратам на рабочую силу по регионам или по видам деятельности. В этой модели ограничимся вычислением минимального, максимального и среднего значений.

Таким образом, месячные расходы на общественные работы составят от 9 до 50,1 млрд руб., а годовые от 108 до 608,4 млрд руб., соответственно. При принятии среднего значения оплаты общественных работ в размере 27071,1 руб. месячные расходы на общественные работы составят 29,6 млрд руб., годовые - 354,7 млрд руб.

Напомним, что в федеральном бюджете на 2016 г. заложено 4448 млрд руб. на социальную политику [11] при планируемом дефиците бюджета в 2361 млрд руб. Таким образом, можно сделать вывод, что политика общественных работ во всех своих вариантах, кроме оплаты по МРОТ, является весьма затратной для федерального бюджета.

По итогам исследования была получена модель рынка труда, которая может быть пригодна для использования студентами экономического профиля, а также при проведении прикладных исследований.

\section{Лuтература}

1. Боев В.Д. Исследование адекватности GPSS World и AnyLogic при моделировании дискретно-событийный процессов. СПб.: Военная академия связи, 2011. 404 с.

2. Борисов Е.Ф. Экономическая теория: учеб. М.: Юрайт-Издат, 2005. 399 с.

3. Гражданский кодекс Российской Федерации (часть первая): Федеральный закон от 30.11.1994 № 51-Ф3 (ред. от 30.12.2015) [Электронный ресурс]. Доступ из справ. правовой системы «КонсультантПлюс».

4. Занятость и безработица в ноябре 2015 года. URL: http://www. gks.ru/ bgd/ regl/ b15 01/IssWWW.exe/Stg/d11/3-2.doc (дата обращения: 25.01.2016).

5. Киселева M.В. Имитационное моделирование систем в среде AnyLogic: учеб.-метод. пособие. Екатеринбург: УГТУ-УПИ, 2009. 88 с. 
6. Колемаев В.А. Экономико-математическое моделирование. Моделирование макроэкономических процессов и систем: учеб. для студентов вузов, обучающихся по специальности 061800 «Математические методы в экономике». М.: ЮНИТИ-ДАНА, 2005. 295 с.

7. Куприяшкин А.Г. Основы моделирования систем: учеб. пособие. Норильск: ФГБОУ ВПО «Норильский индустриальный институт», 2015. 135 с.

8. Напсо И.М. Моделирование социально-экономических систем // Вестн. Адыг. гос. ун-та. 2006. № 1. С. 85-87.

9. Некипелов А.В. Отечественная историография «Нового курса» президента Ф.Д. Рузвельта // Вестн. Челяб. гос. ун-та. История. 2012. № 25 (279). С. 98-103.

10. О минимальном размере оплаты труда: Федеральный закон от 19.06.2000 № 82-Ф3 (с изм. и доп. от 14.12.2015 № 376-Ф3).

11. О федеральном бюджете на 2016 год: Федеральный закон от 14.12.2015 № 359-Ф3.

12. Сокольская E.E., Двореикая В.И. Математическое моделирование в экономике // Coвременные наукоемкие технологии. 2014. № 5-2. С. 177-178.

13. Токарева A.M. Рынок труда Российской Федерации и его особенности // Экономика и бизнес: теория и практика. 2015. № 9. С. 98-100.

14. Тореев В.Б. Рынок труда и стратегии поиска работы // Народонаселение. 2013. № 3. C. $38-51$.

15. Труд и занятость в России. 2015: стат. сб. / Росстат. М., 2015. 274 с.

16. Чукреев П.А., Корытова Е.В. Занятость населения и её регулирование: учеб. пособие. Улан-Удэ: ГОУ ВПО «Восточно-Сибирский государственный технологический университет», 2010. $216 \mathrm{c}$.

17. Экономическая активность населения (по результатам выборочных обследований). 2014: стат. сб. / Росстат. М., 2014. 143 с.

Porfir'ev E.E., post graduate student from the Institute of economics of the Ural Branch of Russian Academy of Sciences (Ekaterindurg, Russia). E-mail: prosoft06@mail.ru

\section{SIMULATION OF CURRENT TENDENCIES IN RUSSIAN LABOR MARKET}

Keywords: agent-based models; unemployment; mathematical simulation; community services; labor market; labor forces; economic agents.

The article describes the creation and analysis of agent-based model, which reflects the current position of the Russian labor market. The aim is to create a model which describes the current situation in the labor market and which is able to become a base for modeling the situation course of events.

Agent-based models is a relatively new trend in the modeling of social-economic systems. They base on the idea that person, company and the household are economic agents with their characteristics and exigencies.

The reason to choose such topic is the high relevance of the research of the current Russian labor market position and possible trends in this market. Primarily, interest in such studies is subjected to the crisis in the Russian economy, which influence on the real economy sector. The scientific novelty of this work is stated in the use of agent-based modeling method in relation to the current situation on the Russian labor market. The main aspect of this approach is the "top down" simulation, the economic position of individual agents formed in the overall picture, which can be observed in the labor market.

Two alternative scenarios are proposed besides current situation modeling. The first suggests the employment of the unemployed in community services. The second scenario supposes the community services and the creation of new workspaces providing permanent employment by the state. Construction of alternative scenarios enabled to display graphically the impact of government support measures on the level of employment. The probable amount of financial package of community services is estimated.

The result of the research is the implication for a high burden on the budget, which may be caused by a policy of community services.

The model of the labor market was obtained as a result, which may be suitable for economic profile of students use, as well as for research applied. 


\section{References}

1. Boev V.D., Issledovanie adekvatnosti GPSS World i AnyLogic pri modelirovanii diskretnosobytijnyj processov [Research of the adequacy of GPSS World and AnyLogic for modeling discrete event processes]. St. Petersburg, Voennaya akademiya svyazi, 2011. p. 404. p. 399.

2. Borisov E.F., Ekonomicheskaya teoriya [Economic theory]. Moscow, Yurajt-Izdat, 2005,

3. RF Federal Law "Civil Code of the Russian Federation (Part One)" of November 30, 1994 № 1 FZ (as amended by Federal Law of December 30, 2015 № 457 FL). (In Russian).

4. Zanyatost i bezrabotica $\mathrm{v}$ noyabre 2015 goda [Employment and unemployment in November 2015]. Available at: http://www.gks.ru/bgd/regl/b15_01/IssWWW.exe/Stg/d11/. (accessed: 25.01.2016).

5. Kiseleva M.V., Imitacionnoe modelirovanie sistem v srede AnyLogic [Simulation of systems in software package AnyLogic]. Ekaterinburg, UGTU-UPI, 2009, p. 88.

6. Kolemaev V.A., E'konomiko-matematicheskoe modelirovanie. Modelirovanie makroe'konomicheskix processov i system [Economic and mathematical modeling. Modeling of macroeconomic processes and systems]. Moscow, YuNITI-DANA, 2005, p. 295.

7. Kupriyashkin A.G., Osnovy modelirovaniya system [Basics of simulation systems]. Norilsk, FGBOU VPO "Noril'skij industrial'nyj institute", 2015, p. 135.

8. Napso I.M., Modelirovanie social'no-e'konomicheskix sistem [Modeling of socio-economic systems]. Adyghe University Herald, 2006, no. 1, pp. 85-87.

9. Nekipelov A.V., Otechestvennaya istoriografiya «Novogo kursa» prezidenta F.D. Ruzvel'ta [Domestic historiography of "New Deal" of President Franklin D. Roosevelt]. Chelyabinsk University Herald. History, 2012, no. 25 (279), pp. 98-103.

10. RF Federal Law “On the minimum wage” of June 19, 2000 № 82 FZ (as amended by Federal Law of December 14, 2015 № 376 FZ). (In Russian).

11. RF Federal Law “On the Federal Budget for 2016” of December 14, 2015 № 359 FZ. (In Russian).

12. Sokolskaya E.E., Dvoreckaya V.I., Matematicheskoe modelirovanie v e'konomike [Mathematical modeling in Economics]. Sovremennye naukoyomkie texnologii [Modern high technologies], 2014, no. 5, part 2, pp. 177-178.

13. Tokareva A.M., Rynok truda Rossijskoj Federacii i ego osobennosti [Labor market and the Russian Federation features], E'konomika i biznes: teoriya i praktika [Economy and Business: theory and practice], 2015, no. 9, pp. 98-100.

14. Toreev V.B., Rynok truda i strategii poiska raboty [Labor market and job search strategies], Narodonaselenie [Population], 2013, no. 3, pp. 38-51

15. Trud i zanyatost v Rossii. Statisticheskij sbornik [Labor and Employment in Russia. Stat. Review]. Moscow, Rosstat Publ., 2015. 274 p.

16. Chukreev P.A., Korytova E.V., Zanyatost naseleniya i eyo regulirovanie [Employment and its regulation]. Ulan-Ude, GOU VPO "Vostochno-Sibirskij gosudarstvennyj texnologicheskij universitet", 2010. 216 p.

17. Ekonomicheskaya aktivnost naseleniya (po rezul'tatam vyborochnyx obsledovanij). Statisticheskij sbornik [Economic activity of population (based on sample surveys). Stat. Review]. Moscow, Rosstat Publ., 2014, p. 143.

Porfi'ev E.E. Modelirovanie tekuschih tendentsiy na rossiyskom ryinke truda [Simulation of current tendencies in Russian labor market ]. Vestnik Tomskogo gosudarstvennogo universiteta. Ekonomika Tomsk State University Journal of Economics, 2017, no 37, pp. 85-94. 